\title{
Importance Of Technology Investments In The Logistics Service Providers: A Case Study Of UPS And Its Use Of Online Tools
}

Steven R. Clinton, Robert Morris University

\begin{abstract}
Logistics service providers must become competitive in mail delivery, customer relationship management (CRM) strategies, and technological integration. UPS, for example, uses a logistics service strategy to effectively manage the logistical requirements for its 7.9 million daily customers. Within the competitive market of parcel delivery, logistics service providers must routinely invest in technology in an e-commerce environment in order to successfully develop strategies to meet the demands of B2B and B2C customers, while accomplishing customer efficiency and return on investments. This strategy has helped logistics service providers to leverage their core competencies; in particular for UPS to become the shipping industry leader in e-commerce. This research outlines the history, inner workings and culture of UPS, while simultaneously examining the subtleties, which have led to the company's extraordinary success. Throughout this analysis, the research will show that in fact there is a rather complex model, which allows UPS to function, as it incorporates $B 2 B, B 2 C$, investments in technology and on-line tools into an outcome of seemingly effortless customer efficiency.
\end{abstract}

\section{INTRODUCTION}

\section{Competitive Nature Of Successful Logistics Service Providers}

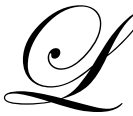

ogistics service providers are rapidly becoming more competitive in mail delivery as international competition become more intense by leveraging customer relationship management (CRM) strategies (Anton and Petoufoff, 2002; Smith, 2005a; Xue and Harker, 2002) and technological integration (Smith, 2004, 2005b, 2005c). Many logistics service providers, such as the United Parcel Service (UPS) brand and Federal Express (FedEx), have been built on excelling at its core business, which is package delivery. In the past 90+ years, the scope of successful logistics service providers' business has changed dramatically, but its essence has not; namely providing a vast array of logistical and distribution services for its global customers by focusing on a tradition of customer-support culture. This customer-focused legacy is fundamental to logistics service providers' ability to attract, retain and keep the trust of their customers.

For example, typically the management at logistics service providers' business worldwide is hallmarked by their attention to customer needs as a key element to their future success. From the integration of physical delivery and electronic commerce to marketing and selling, logistics service providers are providing solutions tailored to meet the complex needs of all their customers, through B2C (business-to-customer) and B2B (business-to-business) strategies. As a result, customer satisfaction can be measured providing decision makers with information of what is working, what is not, and why. Logistics service providers may measure their critical success factors against the belief that corporate commitment to core values and ethical decision-making are the foundations for sustainable competitive advantage, which ensures a company's long-term viability. This commitment creates success by allowing their customers and employees to development avenues of trust that are backed with integrity through its business transactions (Smith, 2002). This attention to the customer service cycle, as reflected in Figure 1, must be able to take logistics service providers' customers where they want to go today but anticipate where they will need to be tomorrow. 
Figure 1: Successful logistics service providers must provide attention to the customer service cycle.

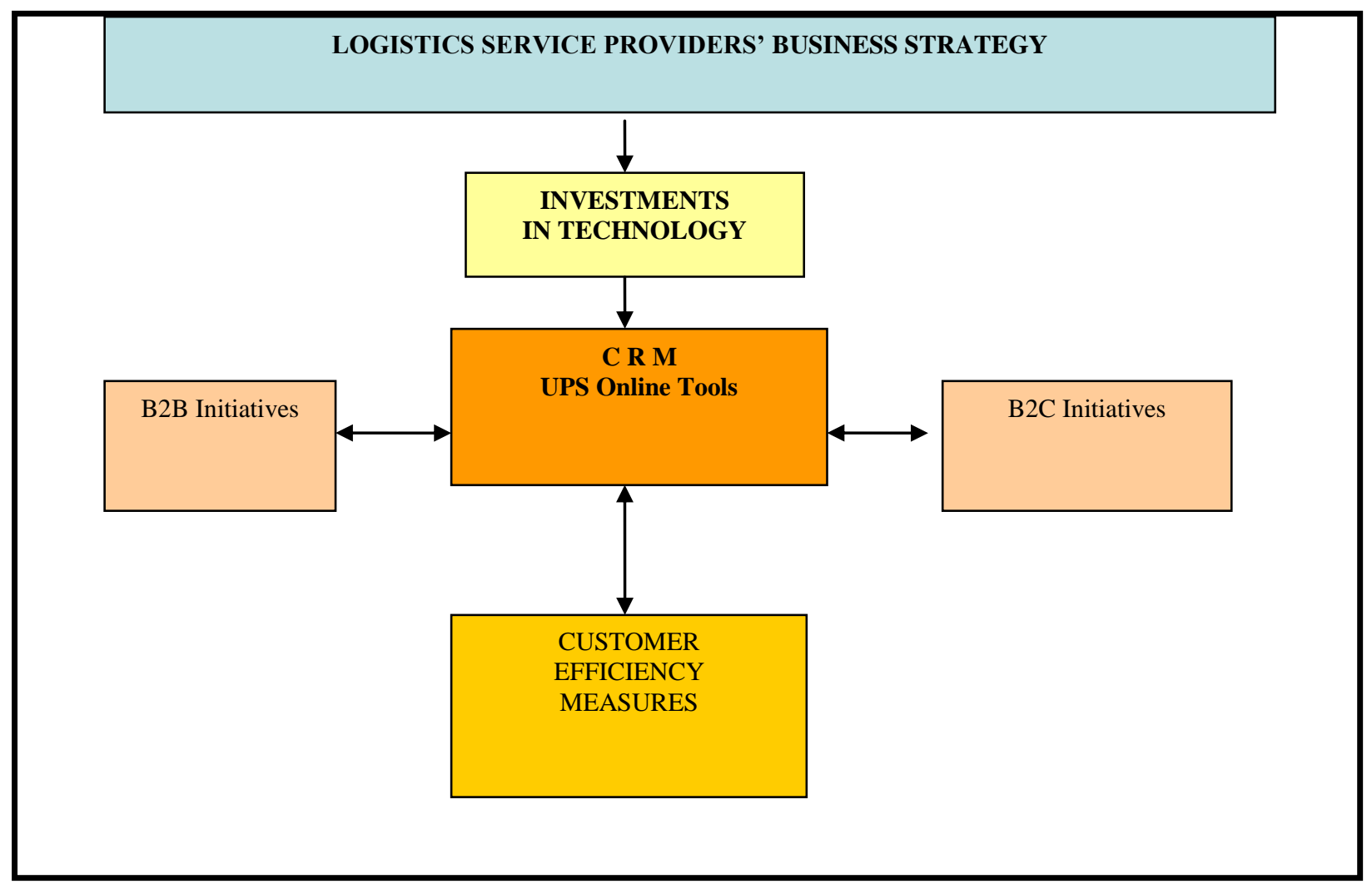

\section{Strategic Investments In Technology}

Typically, logistics service providers that had significant investments in technology that represent a huge part of the company's business strategy, tend to be able to offer the flexibility to meet the demands of its customers through B2B and B2C relationships. Management must be able to leverage their investments it spends on technology and operating systems so that they are properly directed toward the goal of providing the highest possible service to each customer. Essentially, there many millions of opportunities each day through which logistics service providers and their organizational capabilities are able to impact their customer's perception of service. The customer's decision to use a particular logistics service provider instead of their competitors can be either reinforced or undermined each day by its customer support systems that are carefully monitored for optimal performance. Service to the customer lies at the heart of every successful company, all the technology in the world will not make much competitive difference with out a strong customer support component. To enable an organization to manage and coordinate customer interactions across multiple channels, departments, lines of business, and geographies, many logistics service providers utilize CRM-related systems (Customer Relationship Management), which employs an integrated approach to identify, acquire, and retain customers; to help maximize the value of every customer interaction and drive superior corporate performance.

A basic outline of logistics service providers' strategy can be found in Figure 1. Although zero defects are not a probable instance in the service industry (Smith and Offodile, 2007), there are several logistics service providers, such as UPS and FedEx, that are setting many important standards to formulate processes of reengineering and technological advancements that will make it possible for total quality with efficiency in customer 
satisfaction. This may not eliminate zero defects in the packaging and delivery system, but it will continue to provide attain, and precision.

\section{CASE STUDY OF LOGISTICS SERVICE PROVIDERS: UPS}

\section{Business Strategy Formulation}

During the early years of the development and acceptance of logistics service providers, UPS and its industrial profile remained relatively low. Their slogan, "Best Service, Lowest Rates" was directed to the customer's most important concerns. It spoke of reliability and affordability. During the 1980s, reliability and affordability took UPS in a new direction; namely they invested millions of dollars in information technology (IT), fleet of airplanes, and many other technological improvements in order to become more competitive. They added new services, expanded business parameters, and challenged themselves into the global operations network. Even though they exceeded premium express services offered by new competitors, most of the public's perceptions of UPS remained the same; basically those perceptions were based on dependable routine ground delivery and remained the foundation for most logistics service providers. UPS has spent over a billion(\$) per year since the mid 1980s on their technology infrastructure and in the acquisition of knowledge capital, including a massive training effort to educate their people on the business implications of technology as well as the activities of the Strategic Enterprise Fund (SEF). The SEF, unlike most corporate venture funds, invests primarily in younger and more innovative companies, perhaps not for only financial gain, but to better understand new market spaces that will affect logistics service providers' best business practices. Present, from such practices, UPS may reap the rewards, since they are the shipping industry leader in e-commerce, which has a significant correlation to their technology expenditures.

\section{E-commerce Initiatives}

Many activities at UPS, as well as other logistics service providers over the past few years can be tied to the development of e-commerce, which is internally referred (from a number of personal interviews of company officials in the Pittsburgh area, as "enabling global commerce"). New digital and physical realities in the logistics arena and its capabilities have been frequently added and accessibility to their services has been improved with UPS Online Tools to reduce e-commerce transaction friction. They do this on the digital front by providing access to their information systems over the Internet; on the physical side, by purchasing Mail Boxes Etc ${ }^{\mathrm{TM}}$ and integrating it into their own UPS Stores and also having UPS shipping centers in Office Depot locations. According to Puscas (2004), the basics of UPS and its business strategy is to integrate its traditional infrastructure within the Internet (this may include leveraging the capabilities of e-commerce and logistics management). As for the customer, essentially it means more accurate and rapid deliveries at a reasonable cost. Hence, what is needed is an infrastructure that can accommodate and span local cultures, customs requirements, regulations and different business hours (Smith and Offodile, 2007). In tandem with the physical infrastructure a sophisticated information system is needed to integrate each member of the supply chain. The management at most logistics service providers should be dedicated to helping their customers manage their supply chains. Logistics management includes quality assurance and testing, after-sale servicing and state-of-the-art supply-chain information systems to track products through the entire product lifecycle. Interestingly, as noted by Puscas (2004), UPS is using international trade rules to challenge public postal services in many countries (including Canada and Germany) to open up opportunities for UPS. By intensely looking for opportunities within the General Agreement on Trade in Services (GATS) and other international trade and investment agreements, UPS is looking to privately provide services that have traditionally been controlled by public entities. Therefore, to gain competitive advantages, many logistics service providers are trying to use international connections and collective leverage to gain access to new markets.

E-commerce is not seen as a separate category at many logistics service providers, including UPS, but as the transition to global commerce; thus defining how these companies will differentiate among themselves and compete in the new economy. Based on a personal interview with Alan Amling (Wan, 2002), the UPS e-commerce director, it is suggested that UPS basically defines e-commerce as the use of network communication technologies to conduct business, which is much more than just selling goods over the Internet. The definition includes 
communications over the Internet, EDI (Electronic Data Interchange) activities, fax, phone, as well as a host of mobile applications; and all this technology applies to the businesses processes that make commerce happen as well. E-commerce is about leveraging new technologies to improve communications with customers and trading partners; leveraging the new communications platform, where entirely new and improved business models can be developed. For example, a recent advertising campaign, "Moving at the Speed of Business," began with four strategic pillars; namely globalization, timeliness, flexibility, and technology. This campaign conveys a fundamentally changed company, while performing with a sense of urgency in an environment of rapid and continuous change. This particular campaign has enabled them to communicate the power of the UPS brand in customer-driven, information based, and time-definite delivery services.

Probably the highest priorities for many logistics service providers over the next few years is to deploy technology that allows these providers to continue introducing new services, and to provide customers with comprehensive information about their shipments. When they are combined in logistics solutions, they become very powerful indeed. Logistics service providers must stay ahead of customer requirements so they can deliver the precise logistics capabilities they need, when they need them, to fulfill the promise of commerce in the new millennium. In order to continue being an industry-shipping leader, logistics service providers must be able to take their customers where they want to go today, but anticipate where they will need to be tomorrow.

\section{CRM Initiatives}

With 2003 revenues at $\$ 33.5$ billion (as retrieved from financials from ups.com), UPS and its clientoriented website and the daily service of approximately 7.9 million customers, UPS is not only a financial juggernaut, but also a savvy and streamlined customer-oriented machine that is mirrored by many competing logistics service providers. Recently for it efforts in customer commitment and satisfaction, UPS was ranked highest in customer satisfaction by J.D. Power and Associates for all types of package delivery, which including ground, air and international service segments (McManus, 2004). However it is important to understand the philosophy, services and commitment to excellence that are employed by the company, in order to ascertain the true level of motivation that keeps its 357,000 employees pursuing individual goals of excellence.

Customer Relationship Management (CRM) is a vital issue in the day-to-day business world. It is a way to express having the ability to organize and maintain a connection with clients, customers and service agents, across multiple communications channels, including web-enabled services, properly staffed call centers, field sales, and dealers or partner-enhanced networks, with regards to business relationships and customer satisfaction. The challenge is to make it as easy as possible for customers to do business with the organization any way they want, at any time, through any channel, in any language or currency, and to make customers feel that they are dealing with a single, unified organization that recognizes them at every touch point. In essence, streamlined and transparent customer support services. Across every sector and industry, effective CRM is a strategic imperative for corporate growth and survival. Research has shown (Smith, 2002; 2004b; Rupp and Smith, 2004) that companies that create satisfied, loyal customers have more repeat business, lower customer-acquisition costs, and stronger brand value; all of which translates into better financial performance. CRM puts the customer at the heart of the organization. Tailoring communications, systems, processes and procedures around your customer needs are vital building blocks that define support system systems.

Most logistics service providers rarely consider their function merely as delivery companies, but part of an overall strategy of customer satisfaction enterprise, with customer needs being the companies' driving force. Its previous emphasis on operations efficiency and reliability, following traditional sources of competitive advantage (Porter, 1991, 1996, 1998, 1999, 2001), has significantly shifted to a customer orientation, focusing primarily on customer needs. For example, UPS has committed a significant amount of time and energy to shift its corporate culture from mainly operational efficiency to a perhaps more balanced approach that includes customer needs and desires (Costides, 2003). Ultimately, the goal of most logistics service providers is to make it easier for customers to do distribution-enhanced businesses. As noted by Hallowell (1999), people really are the most precious resource; as technology's competitive differences keep disappearing, if the human touch or human moment is removed, technology is worthless in adding value to services. But as cultural boundaries within organizations weakened, 
individual fiefdoms of information gave way to sophisticated applications that could span business functions. By doing so, these CRM-related systems applications created the vision of a single view of the customer. For the first time, organizations could track and analyze shifting customer needs, link marketing campaigns to sales results, and monitor sales activities for improved forecasting accuracy and manufacturing demand.

CRM systems are essential components of a customer-focused business strategy that aims at maximizing profit by increasing customer retention and value. To put this strategy into action means viewing selling no longer as a one-time transaction but as a long-term cross-functional task, communicating with customers targeted and individually, implementing customer-centric business processes and supporting them with CRM technology. CRM systems are a business strategy to select and manage customers to optimize long-term value. CRM requires a customer-centric business philosophy and culture to support effective marketing, sales, and service processes. CRM applications can enable effective customer support activities, provided that an enterprise has the right leadership, strategy, and culture. As per a CRM-related strategy, a company employing CRM manages the important internal and external relationships with the customers of the company through the manipulation of information about them. The information is shared and transformed into knowledge. Knowledge enables the company to understand the customer, and this information in turn is used to align the organization's capabilities in order to deliver better value to customers. To satisfy customer needs, the company must have a technological architecture which when utilized properly results in successful CRM practice. Technology is essential to the implementation of a CRM strategy as it underpins the business process.

UPS, as well as other logistics service providers, has invested heavily to make the needed changes in IT. It was an investment that has allowed them to connect with customers in a number of different ways. This investment has shown loyalty to their customers by creating a range of electronic commerce services. In other words, they are going to the places their customers do business, as opposed to trying to drive them to places that are easiest for logistics service providers to serve them. Typically customers usually reciprocate through being connected electronically by increasing their shipping volume and they tend to stay loyal over the long haul. By providing wide-ranging logistics services, competitive logistics service providers essentially become a key part of the customer's supply chain. For example, in 1999, UPS had annual revenue of $\$ 27.1$ billion and carried over 3.25 billion packages using its ground fleet of 149,000 vehicles and air fleet of almost 600 aircraft (UPS-owned and chartered). UPS services more than 200 countries and territories around the world including every address in the U.S. Globally speaking, UPS has 358,000 employees, 320,000 of which are in the U.S., making it the fourth largest employer in the country ("UPS e-commerce" 2007).

As the largest express carrier and package carrier in the world, proper CRM initiatives at UPS allows them to handle over two million packages a day and deliver to more than 200 countries. Their fleet of 600 aircraft completes more than 1800 flights daily into more than 700 domestic and international airports. They are among the 10 largest airlines in the world ("Customer Relationship Management and UPS" (2007a, 2007b). UPS has long used a customized bid pricing system to help manage the more than 100,000 competitive bids that it makes every year in North America. Not surprisingly, given this track record of success, a wide variety of companies from many different industries, ranging from telecommunications to semiconductor manufacturing to industrial goods and freight transportation, have invested in pricing and revenue optimization techniques. However, in each case, successful pricing and revenue optimization techniques require clean, accurate, and timely data, which is especially important in managing the CRM initiatives at most competitive logistics services providers. Software applications allow logistics services providers to continually monitor its application infrastructure performance and be alerted when application performance parameters exceed user-established thresholds. When software applications detect a performance problem, it usually provides technology support personnel with a thorough set of diagnostic data that pinpoints the specific root cause of application performance degradation and offers suggested alternatives to alleviate the problem.

Specific to UPS, the company's three keys to successful logistics are globalism, connectivity, and service. Basically, globalism means having the capability to provide a preferred standard of service to any customer, anywhere in the world. Being successful at globalism is having a global supply chain provider that understands how things get done in every country where their customers are. Connectivity, when combined with logistics services, 
provides a powerful critical success factor for e-commerce applications. Successful logistics services providers have massive infrastructure that allow them to fulfill its strategy of being as prevalent and user-friendly in the virtual world as in the physical world. UPS, for example, has formed alliances with vendors, such as IBM, to help provide universally standard shipping service features in their software packages used to create Internet-based catalogs. Finally, the next important requirement for any successful logistics services provider is service to their customers (Maselli, 2002; Smith, 2002). All three elements, namely globalism, connectivity, and service, cannot stand alone in providing value to e-commerce. Customer service, quality, and relationship-building cannot be underemphasized, or the business will be moot. The dedication of the UPS-based employees is primarily achieved through two long-standing company policies: employee ownership and training. These policies help promote excellent service because every manager and employee stockholder is working for his/her own business. It shows that the employees have a high level of pride in their jobs and in the company, which hopefully translates into strong loyalty and a shared sense of mission.

\section{CRM-Enhanced Tools}

Technology has opened many additional channels of communication between customer and companies. The two most popular with customers, in addition to the telecommunication, are e-mail and the corporate websites, although mobile communication technologies and their rapid acceptance has significant impact on competitive logistics services providers. However, since customers thrive on access to company information, they are also selecting from a long list of other channels to leverage their communication options. These communication options include all of the following: voice mail, fax-back, kiosk, web-enabled chat rooms, and wireless devices such as cell phones, pagers, PC wireless, iPods, and WAP devices, to name only a few. Management of customer relationships through these additional channels has added electronic aspects to CRM systems and their communication options as well; namely electronic-enhanced CRM (e-CRM). In this section, an attempt is made to bring to light a few of the many e-CRM-based solutions that logistics services providers have recently developed to help their businesses improve customer service, add website functionality, increase time on customers' website, reduce costs, give customers peace of mind and empower buyers.

Selected logistics services providers, such as UPS, have developed customer-intensive information services, such as TotalTrack ${ }^{\mathrm{TM}}$ and MaxiShip ${ }^{\mathrm{TM}}$. TotalTrack ${ }^{\mathrm{TM}}$ is based on a nationwide cellular mobile data system and provides customers with tracking information for all bar-coded air and ground packages. MaxiShip ${ }^{\mathrm{TM}}$ let customers manage the entire distribution process, from the rating and zoning of packages, to preparation of userdefined management reports. In 1999, a new package of UPS Online Tools ${ }^{\mathrm{TM}}$ was introduced and included advanced shipping and logistics applications that provide businesses with the most extensive web-based transportation technology solutions to date. UPS Online Tools ${ }^{\mathrm{TM}}$ includes, but is not limited to, the following customer-enhanced technologies:

1. Enhanced tracking, which enables customers to track packages using their own internally generated reference number. Embedding UPS tracking functionality into a website aids and improves customer service and reduces costs by encouraging receivers to track their shipments online rather than calling a phone center. It may also encourage customers to return to the website to check order status, which provides an opportunity for repeat sales.

2. Published Rate and Service Selection, which enables merchant's customers to compare logistics services providers' rates for different levels of service and select the service that best meets their needs.

3. Address Validation, which detects discrepancies in city-state-zip code combinations and helps companies improve customer service by ensuring that shipping addresses are correct at the point of order.

4. Time-in Transit, which provides the buyer with the time-in-transit in business days for logistics services providers' ground shipment. This helps the buyer choose the best logistics services providers' delivery option to meet their needs.

In 1999, UPS and its vision on technology continued to grow as they partnered with Hewlett-Packard (HP) and developed the industry's first digital document delivery. Some logistics services providers may forgo the activities to develop necessary technology and paid a heavy price in the form of lost business. Document exchange 
activities allow logistics services providers to exchange documents, images and software using encryption and password protection. Along with document exchange is an option, referred to as e-copy, which allow logistics services providers that use multifunction digital copiers to create an electronic copy of paper documents. The ecopy option has a password protected traceable encrypted file attached to it by the document exchange for its secure transportation.

\section{Signature Tracking}

Signature tracking is a program which enables logistics services providers to rapidly obtain the necessary information on proof of delivery; namely the information necessary to collect funds through a proper invoice. This program allows logistics services providers to retrieve this information in seconds (instead of hours or evens days in the traditional approach) through digital signatures and full addresses; hence, increasing accessibility of CODrelated information, reference number and all tracking information.

\section{Rates And Service}

Rates and service option is a user friendly and customer beneficial tool allowing customers to generate specific shipping charges before acquiring logistics services. This program gives customers required flexibility and control of online purchases, allowing the customer to pick which shipping method meets their needs in time and price. This option also allows for a user-friendly layout to search for service charges or for each shipping option along with pull down menus for easy operation. Rates and services options are available in two versions; namely HTML that emulates the page layout found on the UPS website and XML, which allows the customers to customize a format to suit web site or applications design.

\section{UPS Return Services}

Returns management (or reverse logistics) is becoming an integral part of many companies (Smith, 2004c, 2004d, 2005b). From a customer's perspective, product returns are one of the greatest detriments with online purchasing, more progressive logistics services providers, such as UPS, have incorporated a number of CRM-related programs to address this area of reverse logistics. At UPS, for example, they have adopted several reverse logistics programs; namely UPS Return on the Web ${ }^{\mathrm{TM}}$, UPS Returns Plus ${ }^{\mathrm{TM}}$, and UPS Return ${ }^{\mathrm{TM}}$. These programs were designed to significantly reduce the hassle of returning and were designed for the novice to utilize basic aspects of reverse logistics. UPS Returns on the $\mathrm{Web}^{\mathrm{TM}}$ is a program that was initially designed to be a self-service return solution for customers who wish to automate their returns. The consumer, including the delivery of UPS Return label via a browser, completes the return process completely online. UPS Returns Plus ${ }^{\mathrm{TM}}$ is a program option that allows merchants to provide convenient pickup options for prompt returns. UPS Returns ${ }^{\mathrm{TM}}$ is another option that provides several methods to generate package return labels; namely through Authorized Return Service ${ }^{\mathrm{TM}}$, whith preprinted return labels for distribution. Within this program, customers may also use UPS Print Return Label ${ }^{\mathrm{TM}}$, which generates return labels from a standard printer that is within the customer's control; or the customer may use UPS Print \& Mail Return Label ${ }^{\mathrm{TM}}$, which UPS generates and automatically mails a return label to the customer. Lastly, the customer may elect to use the UPS Electronic Return Label ${ }^{\mathrm{TM}}$, which the logistics services provider generates and e-mails a return label to the customer.

\section{Expense Management}

Expense management is an interesting program that contains two relatively innovative solutions that allow a business to run more efficiently (UPS Campus Ship ${ }^{\mathrm{TM}}$ and UPS Flat File Bill Too ${ }^{\mathrm{TM}}$ ). The program allows the company to gain control over and visibility into all the company's shipping activities. UPS Campus Ship ${ }^{\text {TM }}$ is a trademark program of UPS that allows multiple users within an organization to ship, track and other features from any computer that is on the Internet. This program also allows management the power to control shipping service levels by the various cost centers. Other features allow management to create company wide address books, query, sort, and export shipping information. UPS Flat File Bill $\mathrm{Too}^{\mathrm{TM}}$ is another expense management program, via a Microsoft Access Database, with its main purpose being to allow enhanced visibility and analysis into shipping 
costs, allowing management to print reports and export into data files for further analysis. In general, business-tobusiness (B2B) solutions that were analyzed are available from UPS on its website and can be downloaded at no charge. Customer support is also available via e-mail and that as well has no charge.

Specifically, UPS solutions ${ }^{\mathrm{TM}}$ allow companies to customize a shipping program to meet their needs and budgets. UPS, as well as other competitive logistics services providers, has invested significantly into their CRMbased IT programs, enabling them to maintain leadership in a very competitive market. Logistics services providers must continue to meet the needs of their customers and also continue to develop new solutions as technology allows them to accomplish this.

\section{B2B And B2C Strategies}

While the vast majority of competitive logistics services providers' business centers on delivery volume to businesses, they also try to provide carrier services in the business-to-customer (B2C) e-commerce arena as well. The logistics services lines between B2C and B2B blur as an inspection of their unique solutions those logistics services providers have implemented to make coverage of residential deliveries, especially for international locations, more convenient for the customer. In terms of competitive logistics services providers, there are some major key differences between B2C and B2B that must be considered; namely B2B traffic volume is considerable larger, B2B payment method is typically by purchase order (PO), and B2C payment method is usually by credit card. Other key differences between logistics service providers B2C and B2B activities include: negotiation is more common in B2B and the reporting needs are more advanced; relationships and supply chain partnering are much more important in a B2B environment; switching costs are typically higher in $\mathrm{B} 2 \mathrm{~B}$, and for many larger logistics companies the delivery destination in $\mathrm{B} 2 \mathrm{~B}$ e-commerce is typically commercial.

In B2B markets, some logistics service providers are forced to scale down in personal and overall expenses, while other companies are looking for the best solutions to streamline time and efficiency. Modern marketplaces are usually very fast paced, with technology being a major IT solution to streamline operations. The parcel delivery business has to recognize these demands and develop the proper e-commerce solutions before their competition does. The parcel delivery industry, with new technologies and solutions, is allowing them to involve themselves ever deeper into their customers' business through transparent supply chains.

The enormous amount of technological resources that are incorporated into logistics service providers' methods of contacts, especially those that connect with and service its customers, result in better customer relationships. Competitive logistics service providers typically use technological resources to promote contracts directly (person-to-person), via mobile technology (wireless), and extensive virtual services network (Internet/integrated communications). For example, as previously mentioned, UPS interacts with 7.9 million customers on a daily basis; however, as per the company's website (ups.com), this amount includes customer pickups of 1.8 million and deliveries totaling 6.1 million. Due to its global presence, which encompasses approximately 200 countries and is serviced through its facilities in Atlanta, Georgia, management realized that such huge volumes must be based on highly developed technology to maintain efficiency and keep prices competitive. This development can be said of all competitive logistics service providers. From this requirement for integration of technology coupled with person-to-person contact, sprung one of the most useful innovative and eventually key components used by UPS delivery personnel, referred to as the handheld Delivery Information Acquisition Device (DIAD), which was designed to give real-time functionality and tracking capabilities to its employees. However, one of the true benefits of this device is that not only does it track such mundane data such as shipping, times, pertinent addresses, and package specifications; it also solved a common problem inherent in many companies, which deals with the issue of reverse logistics.

While many companies have the ability to interact with clients via the mail through their shipping departments, the ability to successfully return packages to their source, using the most effective and cost sensitive methods often elude even the most capable of companies. However, many logistics service providers have realized that tracking the desired location, time and contact for each package was not enough. The management at UPS, for example, eventually realized that the key was to do tracking in a real-time environment, which was accessible to 
employees and customers alike in order to create a truely dynamic, scalable, and interactive environment. Competitive logistics service providers must strive to use technological solutions to enhance its logistics functions. UPS Logistics ${ }^{\mathrm{TM}}$, which has made their focus to be logistically oriented, deals with logistical solutions by understanding their approach to logistically oriented problems can give substantial insight into the company's thought process and methods. UPS Logistics ${ }^{\mathrm{TM}}$ distinguishing factor is that it uses a general strategic model (as demonstrated in Figure 1), which helps to provide "the client with a single point of contact" (Van Hoek, 2001, p. 464 ) without disrupting the flow of information and or knowledge.

Virtual services and the successful integration of technology play another business critical role in logistics service providers' direct ability to connect to, service, and successfully manage millions of customers. For example, while UPS is afforded the ability to contact and do business through its website, which allows users to track their shipping order through My UPSTM, huge centers, such as its Worldport ${ }^{\mathrm{TM}}$ division, which process an average of 600,000 packages nightly and allows over 100 flights in and out of its four-million plus facility need a substantially greater degree of power and scalability in order to make customer transactions and order fulfillment possible (Brewin, 2004, p. 1).

The Worldport ${ }^{\mathrm{TM}}$ division is one of $750+$ domestic and 1,748 global operating facilities used to make the existence of UPS possible and through advanced technological integration makes Worldport ${ }^{\mathrm{TM}}$ possible. Another technology driven investment into technology involved the \$100 to 120 million investments that UPS made in 2001 for a cordless advanced scanner ring created by Bluetooth, Inc. that has the ability to basically capture tracking data from package labels and wirelessly transmit data to a terminal and to a central computer without a need for excessive equipment (Lipset, 2003). Field use of extremely advanced technologies by employees should be able to significantly improve their productivity measures. This trend should not only led to more productive and less stressed employees, but should also create more satisfied and loyal customers who experience positive lifetimevalue transactions with each interaction with the company.

\section{Customer Efficiency/ROI}

Quality initiatives undertaken by successful logistics service providers may be grouped into a number of categories that work well within their organizations, based off a service organization committed to quality. The basic step of gathering customer feedback is essential to any service-oriented organization. Customer feedback data are taken from customer service calls, Internet comments, and questionnaires. Once compiled, managers of logistics service providers typically analyze the data for patterns via data mining techniques and recognize their limitation for application and feedback purposes. Initiatives that improve the service to customers are then planned and implemented. As noted by Nelson (1995), the process of establishing customer councils to assess their performance against the needs of the marketplace is extremely important. UPS, as well as other logistics service providers, want to give their customers a chance to express opinions and ideas about their logistics services to determine if they are meeting their shipping needs. There is evidence that would suggest that there is a direct correlation between companies' IT budgets and their sales (Smith, 2004a, 2004b, 2004c, 2004d). This would indicate that ignoring technology not only wastes unnecessary time and energy, it also is not conducive to an effective customer-oriented business strategy. Logistics service providers must become aware of the value of implementing these customer friendly methods of business and attempting to meet consumers' expectations, while making sure they can understand clearly what customers really think and want from their carrier through proper communication channels.

Another step formulated for customer efficiency involves all stakeholders involved in logistics service providers; namely intangible strategic aspects dealing with human resources (HR), such as smart recruiting, good salaries and benefits, and ongoing training and development (Bowen and Lawler, 1992; Ingram, 1996; Jackson, 1985; Wilson, 1995). It also includes intangible aspects of achieving high levels of professional performance for an organization's employees, such as motivation, communication, and sense of ownership and belonging. Turn-over rates for full-time employees at UPS are generally two-percent annually. As noted by Nelson (1995), when service is your business, perhaps the best way to guarantee the satisfaction of your customers is by ensuring the personal satisfaction of your employees. To achieve a low turn-over rate for full-time employees, one tactic is to develop an extensive internal communications program. For example, internal communications programs enable UPS to 
capture and make use of their people's knowledge of their jobs, their tools, and most importantly, the customers that they serve. Involving the employees empowers them to make decisions with the customers in mind.

Another major consideration for ensuring quality customer service for logistics providers is to create an effective service recovery program. As suggested by Del Prete (1996), "do the right things and do them right the first time" is a method that should ensure customer satisfaction. UPS delivers about 12 million packages around the world every day and although zero defects are not a probable instance in the service industry, logistics services providers need to be active in setting the standards to formulate processes of re-engineering and technological advancements that will make it possible for total quality with efficiency in customer satisfaction. This may not eliminate zero defects in the packaging and delivery system, but it will continue to provide excellence, and precision. As suggested by Nelson (1995), it is possible to turn a service failure into a stronger relationship with the customer. By moving quickly and skillfully to correct a service failure, the customer is typically watching closely for the company's contingency plan and how well it works in order to establish creditability with the customer. Logistics services providers need to utilize their recovery program to make it possible to turn a service failure into an even stronger relationship with the customer.

To make sure customers are clearly understood, many logistics services providers, including UPS, have developed a Customer Satisfaction Index or CSI. This index is composed of sophisticated computer systems and employee-training programs associated to promote customer satisfaction. This system gathers vital information on many elements that contribute to key service components, places the data in a database system to measure perceptions about what customers think of the logistics services providers' image, customer orientation and each customer's overall satisfaction with UPS's performance. CSI is not so precise it can tell management how close a given logistics services provider is to being the ideal carrier for a particular customer base, but it does allow for a degree of competitive benchmarking in the logistics industry. Essentially every region and district at UPS, for example, gets a CSI score. This score is composed from customer feedback and employee comments/concerns to managers and employee presentation. This information is then directly tied to each employee's performance evaluation, which makes quality an integral part of operations since it is incorporated in the compensation system. In addition, this system enables logistics services providers to focus their resources on the issues that matter most to their customers. It also allows them to keep learning and improving their performance just as their competitors do. The goal of any CSI system is to be able to reach a point where each employee's career is at least partially linked to customer satisfaction. Application of a CSI-based system should be a company wide, life-long strategy that is being put together to benefit all logistics services providers' stakeholders. The long-term effects of a CSI-based implemented system should equate to a highly responsive and competitive, as well as profitable, service provider. Increasing customer satisfaction, efficiency, and market share should logically be reflected in higher monetary corporate profits than the competition. For example, when UPS inaugurated its first deliveries to China, it made a promotional effort by naming a plane "China Express" and unveiling its dragon logo. Their first step in this investment was to develop a sales message to gain attention and shape the message to the receivers' interests and benefit. During this period, there was much media attention due to the nature of the initial upfront costs and the commitment UPS provided for China. This investment, which proved very successful for UPS, allowed the logistics services provider to increase its market share globally and advance in Asia.

One of the more recent investments made by UPS is the acquisition of Mail Boxes Etc ${ }^{\mathrm{TM}}$. The new name associated with this acquisition is referred to as The UPS Store ${ }^{\mathrm{TM}}$. Customers will receive lower prices as well as experienced shipping and synchronized commerce and is the largest such offering in retail and franchise history (Sutton, 2002). UPS continued to sell mailing material and services, including packaging, mailbox services, office supplies, copying and notary services, as well as other logistics services. Fortunately, the strategic plan was to not let logistics services decrease, but the operational costs associated with the retail chain to decrease rapidly. Sending packages from The UPS Store ${ }^{\mathrm{TM}}$ generally cost customers approximately $20 \%$ less than before. A partial the reason for this decrease in operational cost is the elimination of using other carriers. FedEx, which was formerly available at Mail Boxes Etc ${ }^{\mathrm{TM}}$, is no longer available. Acquiring these brick-and-mortar locations allows logistics services providers to become competitive by being at the leading edge of customer efficiency. The return on this investment amounts to net profits of approximately 23 million additional dollars per year. As shown for information taken from secondary statistics from the websites at UPS and FedEx, return on IT investments must be worth the price to 
provide enhanced customer quality and satisfaction, as indicated by comparative correlations between UPS and FedEx in terms of a convenience sample of 34 to 48 reported regions or divisions that were available for comparisons. In Figure 2, there is a statistically significant correlation between the IT budget figures as it related to positive growth of annual sales. The same basic conclusion can be said about FedEx and other major logistics services providers. As demonstrated in Table 1, IT budget figures at UPS positively correlate with average daily shipping volumes for various products and regional distribution centers. Table 2 shows a simple analysis of correlations between FedEx and UPS in terms of their IT budgets, effect on sales, net income, and average daily shipping values. Although there were mostly no statistically significant correlations, as shown in Table 2, Part B, there was a fairly strong positive correlation between UPS budget amounts $(\$)$ with UPS sale amounts $(\$)(r=$ $0.899, \mathrm{p}=0.005)$, suggesting that sales revenues are directly tied to logistics services providers budget for customerrelated support services and IT-related applications.

Figure 2: UPS IT Budget correlation to annual sales (indicates a significant correlation),

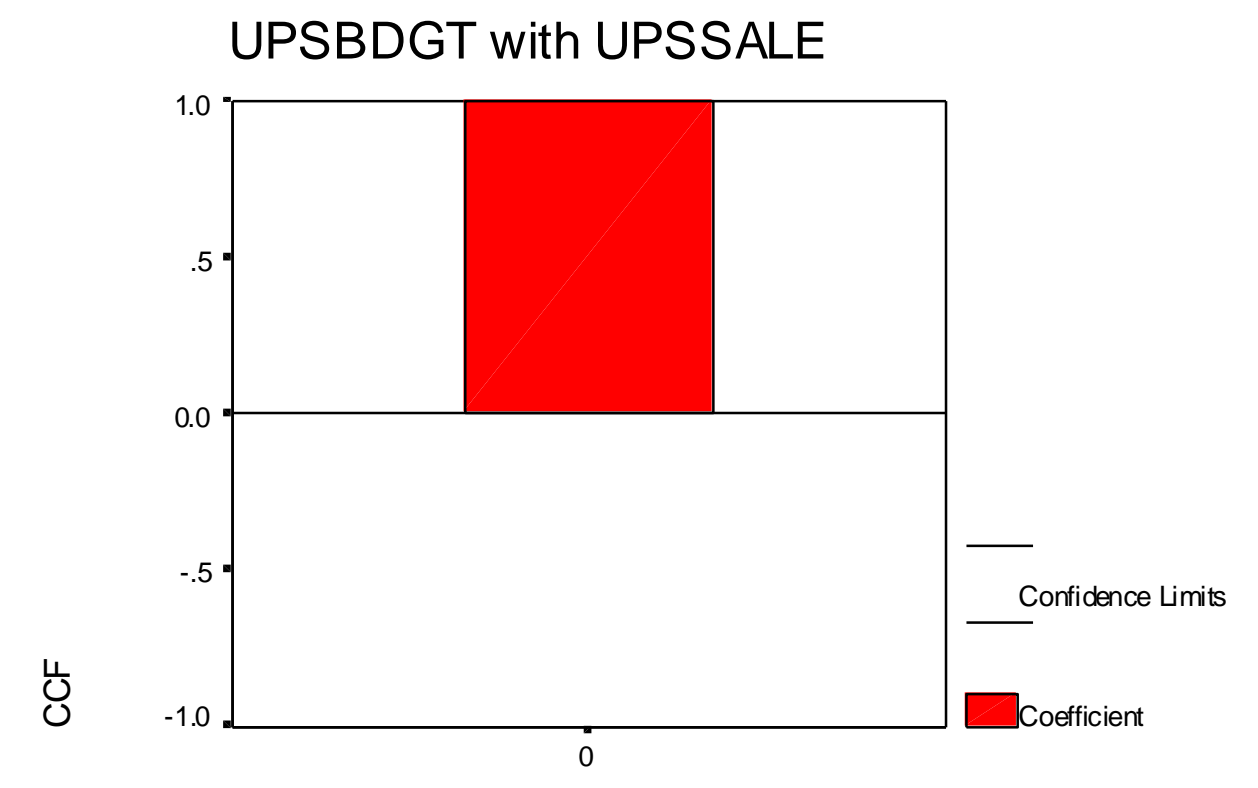

Lag Number

Transfor ms: difference (1)

Table 1: IT budget figures at UPS correlation with average daily shipping volumes for various products and regional distribution centers.

\begin{tabular}{|c|c|c|c|}
\hline & & UPS IT Budget (4) & UPS Average Daily Shipping Volume \\
\hline Sample size & Valid & 34 & 48 \\
\hline Mean & Missing & 1 & 0 \\
\hline Skewness & & 949263333.33 & 13541250.00 \\
\hline Std. Error of Skewness & & 1.019 & -1.689 \\
\hline
\end{tabular}


Table 2: Analysis of correlations between FedEx and UPS in terms of their IT budgets, effect on sales, net income, and average daily shipping values.

Part A. FedEx statistics.

\begin{tabular}{|c|c|c|c|c|c|}
\hline & & $\begin{array}{c}\text { FedEx Budget } \\
\text { Amounts (\$) }\end{array}$ & $\begin{array}{c}\text { FedEx sale } \\
\text { Amounts (\$) }\end{array}$ & $\begin{array}{l}\text { FedEx Net Income } \\
\text { (S) }\end{array}$ & $\begin{array}{c}\text { FedEx shipping } \\
\text { volumes }\end{array}$ \\
\hline \multirow{3}{*}{$\begin{array}{c}\text { FedEx Budget } \\
\text { Amount (\$) } \\
\end{array}$} & Pearson Correlation & 1 & 0.585 & 0.868 & -0.314 \\
\hline & Sig. (1-tailed) & 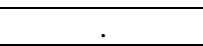 & 0.301 & 0.165 & 0.398 \\
\hline & $\mathrm{N}$ & 37 & 37 & 37 & 37 \\
\hline \multirow{3}{*}{$\begin{array}{c}\text { FedEx sale } \\
\text { Amounts (\$) } \\
\end{array}$} & Pearson Correlation & 0.585 & 1 & .910 & -0.954 \\
\hline & Sig. (1-tailed) & 0.301 & . & .136 & 0.097 \\
\hline & $\mathrm{N}$ & 37 & 3 & 3 & 3 \\
\hline \multirow{3}{*}{$\begin{array}{c}\text { FedEx Net Income } \\
\text { (S) }\end{array}$} & Pearson Correlation & 0.868 & 0.910 & 1 & -0.680 \\
\hline & Sig. (1-tailed) & 0.165 & 0.136 & . & 0.160 \\
\hline & $\mathrm{N}$ & 37 & 37 & 37 & 37 \\
\hline \multirow{3}{*}{$\begin{array}{c}\text { FedEx shipping } \\
\text { volumes }\end{array}$} & Pearson Correlation & -0.314 & -0.954 & -0.680 & 1 \\
\hline & Sig. (1-tailed) & 0.398 & 0.097 & 0.160 & . \\
\hline & $\mathrm{N}$ & 37 & 37 & 37 & 37 \\
\hline
\end{tabular}

Part B. UPS statistics.

\begin{tabular}{|c|c|c|c|c|c|}
\hline & & $\begin{array}{c}\text { UPS budget } \\
\text { Amounts (\$) }\end{array}$ & $\begin{array}{c}\text { UPS sale Amounts } \\
(\$)\end{array}$ & UPS Net Income (S) & $\begin{array}{c}\text { UPS shipping } \\
\text { volumes }\end{array}$ \\
\hline \multirow{3}{*}{$\begin{array}{l}\text { UPS budget } \\
\text { Amounts (\$) }\end{array}$} & Pearson Correlation & 1 & 0.899 & 0.454 & 0.439 \\
\hline & Sig. (1-tailed) & . & 0.005 & 0.350 & 0.355 \\
\hline & $\mathrm{N}$ & 34 & 34 & 34 & 34 \\
\hline \multirow{3}{*}{$\begin{array}{c}\text { UPS sale Amounts } \\
\text { (\$) }\end{array}$} & Pearson Correlation & 0.899 & 1 & 0.229 & 0.065 \\
\hline & Sig. (1-tailed) & 0.005 & & 0.386 & 0.467 \\
\hline & $\mathrm{N}$ & 34 & 34 & 34 & 34 \\
\hline \multirow{3}{*}{$\begin{array}{c}\text { UPS Net Income } \\
\text { (S) }\end{array}$} & Pearson Correlation & 0.454 & 0.229 & 1 & -0.479 \\
\hline & Sig. (1-tailed) & 0.350 & 0.386 & . & 0.261 \\
\hline & $\mathrm{N}$ & 34 & 34 & 34 & 34 \\
\hline \multirow{3}{*}{$\begin{array}{c}\begin{array}{c}\text { UPS shipping } \\
\text { volumes }\end{array} \\
\end{array}$} & Pearson Correlation & 0.439 & 0.065 & -0.479 & 1 \\
\hline & Sig. (1-tailed) & 0.355 & 0.467 & 0.261 & . \\
\hline & $\mathrm{N}$ & 34 & 34 & 34 & 34 \\
\hline
\end{tabular}

** Correlation is significant at the 0.01 level (1-tailed).

\section{GENERAL CONCLUSIONS AND IMPLICATIONS}

In order to create long lasting and positive client experiences, logistics service providers have realized that all members within its organization must not only comprehend its vision, purpose, mission and strategy, but they must live it out every day. Specifically, these tenets of UPS have been conveyed via various mediums throughout the company's domestic and international divisions. Perhaps no media has been more crucial to the success of the competitive logistics service providers' model more so than the benefits gained through its technological resources and the resulting applicability to effect efficiency throughout its business segments. For example, UPS delivers appropriately 12 million packages and documents a day for more than one million regular customers. With such a 
large volume, it relies on technology to maintain efficiency, to keep prices competitive, and to provide new customer services.

UPS's annual IT budget amounts to over a billion dollars. Due to the demands and competitiveness in the market, UPS managers know that the return on this investment must be well worth the price to provide customer quality and satisfactions. UPS has composed a business strategy that covers all aspects of quality controls in the B2B, B2C, CRM-based initiatives, as well as customer efficiency metrics. Customer efficiency - although difficult to measure and monitor, provides logistics service providers with a return on investment (ROI) that is allowing them to increase their market share of the logistics industry. As evident from recent revenue figures, UPS is the leader in the parcel delivery market and set the bar for other carriers to emulate. However, the logistics service providers' arena is a very competitive one and current success is not a guarantee for future success. Logistics services providers must continue to meet and exceed the needs of their customers by continuing to develop new technological solutions and enhance the professionalism of their human elements through innovation, epersonalization, and creative e-commerce and/or e-CRM initiatives.

\section{REFERENCES}

1. Anton, J. and Petoufoff, N. 2002 Customer Relationship Management - The BottomLine To Optimizing Your ROI. $2^{\text {nd }}$ Ed. New Jersey: Pearson Education Prentice Hall

2. Bowen, D.E., and Lawler, E.E., III. (1992, Spring). The empowerment of service workers: what, why, how, and when. Sloan Management Review. Vol.33.

3. Brewin, B. (2001). UPS to deploy Bluetooth, wireless LAN network \$100M-plus project will field 50,000 terminals to 2,000 distribution hubs. ComputerWorld. [Online]. Available: (http://www.computerworld.com/printthis/2001/0,4814,62459,00.html).

4. Costides, N. (2003, July 3). It's a brand new day at Mail Boxes, Etc: the UPS Store undergoes technology transformation prior to assuming brown's brand. Industry and Business News. Franchising World. [Online]. Available: (http://goliath.ecnext.com/coms2/gi 0199-2997943/It-s-a-brand-new.html).

5. Customer Relationship Management and UPS (2007a). [Online]. Available: (http://www.crmtoolkit.com/CustomerRelationshipManagementUps.html).

6. Customer Relationship Management and UPS (2007b). [Online]. Available: (http://www.crmtoolkit.com/CRMTool.html).

7. Del Prete, D. (1996). Good deeds can equal many happy returns. Journal of Marketing News, 30(10): 3-11.

8. Hallowell, E.M (1999). The human moment. Harvard Business Review, 77(1): 58-64.

9. Ingram, T.N. (1996). Relationship selling: moving from rhetoric to reality. Mid-American Journal of Business, 11(1): 5-13.

10. Jackson, B.B. (1985, November/December). Build customer relationships that last. Harvard Business Review, 63: 120-128.

11. Lipset, V. (2003). Brown turns to Bluetooth in $\$ 120$ million WLAN deployment. [Online]. Available: (http://www.wi-fiplant.com/news/article.php/1564881).

12. Maselli, J. (2002). Couriers deliver customer service. Information Week, Issue 891, p. 60.

13. Nelson, K.C. (1995, August/September). Quality in a service organization: beyond grand gestures. Executive Speeches. 10(1): 11-15.

14. McManus, C. (2004). J.D. Power and Associates ranks UPS highest in customer service. [Online]. Available: (http://quote.bloomberg.com/apps/news?pid=conewsstroy\&refer=conews\&tkr=UPS:US\&si).

15. Porter, M.E. (1991). Towards a dynamic theory of strategy. Strategic Management Journal, 12: 95-117.

16. Porter, M.E. (1996, November/December). What is strategy? Harvard Business Review, 74(6): 61-78.

17. Porter, M.E. (1998). Clusters and the new economics of competition. Harvard Business Review, 76(6): $77-$ 90.

18. Porter, M.E. (1999). Creating advantage. Executive Excellence, 16(11): 13-14.

19. Porter, M.E. (2001). Strategy and the Internet. Harvard Business Review, 79(3): 62-78. 
20. Puscas, D. (2004). A look at the U.S. Coalition of Service Industries. [Online]. Available: (http://66.102.9.104/search?q=cache:eIJZXZcSxqAJ:https://publish.ftaaimc.org/Mir/servlet/OpenMir\%3Fd o\%3Dgetpdf\%26id\%3D3483\%26forIE\%3D.pdf+Puscas, + Darren+UPS+Polaris+Institute\&hl=en\&ct=clnk $\& \mathrm{~cd}=5 \& \mathrm{gl}=\mathrm{us})$.

21. Smith, A.D. (2002). Loyalty and e-marketing issues: Customer retention on the Web. Quarterly Journal of E-commerce, 3(2): 149-161.

22. Smith, A.D. (2004a). Information exchanges associated with Internet travel marketplaces. Online Information Review, 28(4): 292-300.

23. Smith, A.D. (2004b). Empirical exploration for a Product Data Management (PDA) System at a major telecommunications firm. Industrial Management and Data Systems, 104(6): 513-525.

24. Smith, A.D. (2004c). E-traveling via information technology: An inspection of possible trends. Services Marketing Quarterly, 25(3):00-00.

25. Smith, A.D. (2004d). Online privacy policies and Diffusion Theory perspectives: security or chaos? Services Marketing Quarterly, 25(3): 53-75.

26. Smith, A.D. (2005a). Identify theft as a threat to CRM and e-commerce. Electronic Government: An International Journal, 2(2): 219-246.

27. Smith, A.D. (2005b) Reverse logistics and their affects on CRM and online behavior. VINE: The Journal of Information and Knowledge Management. 35(3): 166-181.

28. Smith, A. D. (2005b). Exploring the acceptability of biometrics and fingerprint technologies. International Journal of Services and Standards, 1(4): 453-481.

29. Smith, A.D. (2005c). Exploring service marketing aspects of e-personalization's impact on online consumer behavior. Services Marketing Quarterly, 27(2): 89-102.

30. Smith, A.D. and Offodile, O.F. (2007). Exploring forecasting and project management characteristics of supply chain management. International Journal of Logistics and Supply Management, 3(2): 174-214.

31. Sutton, N. (2002, June 7). Exercising a cautious approach to IT pays off for big, small users. Computing Canada, 28(12): 1-6.

32. UPS e-commerce (2007). [Online]. Available: (www.ec.ups.com).

33. Van Hoek, R.I. and Chong, I. (2001). Epilogue: UPS Logistics - practical approaches to the e-supply chain. International Journal of Physical Distribution \& Logistics Management 2 31(6): 463-464.

34. Wan, W. (2002). Interview: United Parcel Service's Director of Electronic Commerce, Alan Amling, on the opportunities and challenges of global electronic commerce. Thunderbird International Business Review, 44(4): 445-449.

35. Wilson, D.T. (1995, Fall). An integrated model of buyer-seller relationships. Journal of the Academy of Marketing Science, 23: 335-345.

36. Xue, M. and Harker, P. (2002, May). Customer efficiency: concept and its impact on e-business management. Journal of Service Research, 4(4): 253-261. 